\title{
Challenges of the Renewable Energy Industry Generate New Demands for Risk Advisory: How to Value an Insurance Package from a Financing Perspective?
}

\section{Emmanuel Leblanc}

Marsh Finances, Head of Structured Products, Tour Ariane- La Défense 9, 92088 Paris La Défense Cedex, France.

E-mail: emmanuel.leblanc@marsh.com

Risks associated with the development and implementation of Renewable Energy (RE) technologies are a major concern both in terms of financing for manufacturers and for the financing viability of projects. Insurance is often perceived as a mandatory and costly cover to secure financing for a project and is rarely considered as a way of improving the overall financing conditions and perspectives. For certain RE projects, such as wind farm or biomass, the use of probabilistic models integrating quantifiable risks in the financing context provides a better overview of the risk potential impacts and the insurance merits. The purpose of this approach is to appraise the most efficient insurance package for the project. The probability distribution of the project cash flows, including risk assumptions, allows one to assess the merits of various insurance options and in particular to test their benefits on the rating of debt and financial covenants. This modelling approach provides a good indicator of the potential risk impacts for RE projects and is also a useful tool to determine the optimum allocation of risks, costs and reserves between the various parties involved in such a project.

The Geneva Papers (2008) 33, 147-152. doi:10.1057/palgrave.gpp.2510156

Keywords: renewable energy; risk modelization; insurance value; financing enhancement

\section{Renewable Energy (RE) industry developments}

In reaction to the major threats of climate change the (RE) sector has been strongly promoted over the last few years and is now one of the core instruments to address climate change risks.

The Kyoto Protocol is only one application of this voluntary policy initiated throughout the world but is very representative of the willingness to implement longterm but sometimes constraining policies to face climate change. Local governments are also playing a major role in this global warming battle with the ability of encouraging the development of RE through tax incentives, local Power Purchase Agreements and other State subsidies. The profitability of this industry is however at stake and only strong political supports can promote the development of the RE industry on a large scale. In this context, the risks associated with the development and implementation of new technologies is a major concern both in terms of financing for the manufacturers and for the financing viability of the projects.

$\mathrm{RE}$ is expected to constitute one-third of the world energy mix by 2050, and in this context the insurance industry is playing its own role by accompanying manufacturers 
and challenging projects. Yet, RE players tend to consider that insurance is only a mandatory requirement of financiers but do not look at it as a true means of enhancing the financing structure (and more importantly to reduce its cost) if the insurance package can be valued from a financing perspective.

This paper illustrates the new services developed by the Marsh subsidiary, Marsh Finances, to fill this gap and promote a different approach to insurance benefits for the RE industry.

\section{New industry means new risks}

One of the major concerns for the industry relates to the technological risk due to the recent nature of RE technologies involved, which are sometimes unproven on a large scale. This is especially true for developing technologies such as wave and tidal energy.

At first sight, it may be less of a concern for the wind farm industry, which is better appreciated because of a greater experience and where the availability of manufacturers' warranties potentially reduces the risk. However, the extensive use of manufacturers' warranties is now representing a threat to the development of this source of energy. Manufacturers' credit risk is becoming an issue in particular for the continuity of services such as maintenance, spare parts production and availability over time.

In addition, the technical challenges posed by the industrial deployment of high-tech turbines (such as the $6 \mathrm{MW}$ E112 Enercon turbines with a $114 \mathrm{~m}$ rotor diameter and a $124 \mathrm{~m}$ hub height) are comparable to the challenges faced by the aeronautic industry. Thus, even "proven" RE technology always represents a challenge for the insurance industry.

The complex engineering processes (notably technical perils in handling, erecting and testing) and procedures are also an issue during the construction period and the maintenance phases. Specialist contractors and dedicated equipment are required for construction and maintenance.

Cat Nat is particularly a core risk for projects in a harsh environment, typically offshore. Although insurance covers exist in theory, they need to be tested for largescale projects. For instance, large upcoming offshore projects in Belgium and in the Netherlands have to consider such cover and more particularly the insurance mechanisms to ensure the ability of the project to meet the debt repayment profile following a major winter storm.

In addition, commissioning risk should not be underestimated in particular for wind farms (local disapproval for aesthetic and noise issues) and in certain circumstances for political risk in developing countries.

\section{Insurance market appetite and capacity in the RE sector}

To meet these specified risks, the market is offering various covers derived from traditional property damage covers, which are continuously being adapted as technology improves and risks are better assessed. 
Depending on the RE type, the insurance market provides different levels of coverage, including:

- Onshore wind. Traditional insurance products are widely available (property damage, business interruption, machinery breakdown and construction risks):

- Most commercialized technology $\rightarrow$ significant operating and loss history.

- But wind technology is still developing and latest innovations induce technological risk

- Photovoltaic, small-scale hydropower and energy from waste. Most traditional insurance products are available:

- Technologies already tested at scale $\rightarrow$ improves risk appreciation.

- Usually located in friendly environments.

- Offshore wind. Traditional insurance products availability is still at stake:

- Increased asset values and risks exposure.

- Increased construction and operating costs.

- More complex exposure - fewer markets are able to write marine risks (requirements for specialist marine reinsurance protection).

- Wave and tidal power. Technologies seem to be the least favoured technologies to date.

\section{New challenges for the insurance market}

To support the continuing development of RE projects, the insurance industry has to meet great challenges before becoming a mature market. However, its long history has demonstrated its ability to adapt to changes and to quickly react to offer new covers for new risks.

Today, the industry's most critical issue is the lack of operating data in part due to the prototypical nature of many RE technologies. In this respect, there is a limited amount of loss information upon which insurance players can base loss projections and pricing. The difficulty to accurately model future loss projections and price risk in an economic and sustainable manner is therefore integrated in the insurance premium as an additional uncertainty factor.

Again, in case of severe damage, the industry may suffer high replacement risk as specialist contractors and equipment are needed, engineering processes and procedures are complex, the technology is constantly evolving and the current market offers limited slot availability with manufacturers.

Finally, the relatively low insured values associated with small-scale projects may also be an issue for underwriters to achieve underwriting profit.

\section{Modelling the value of insurance for a wind farm business plan}

Based on the Marsh experience of the RE sector, Marsh Finances has developed a specific approach to the potential impact of risks from a financing perspective for wind 
farm projects. The purpose of this approach is to appraise the most efficient insurance package for the project through a probabilistic model of quantifiable risks.

The principle is to model the financial projections with different insurance structures and to identify the best structure within a given financing context. The interest is to optimize the insurance structure and thus leverage the financial structure.

Marsh Finances has used this innovative approach for the United Nations Environment Program for which it has performed an Assessment of Financial Risk Management Instruments for Renewable Energy Projects. ${ }^{1}$

The cash flow model allows assessing the potential future revenues from the operation of a wind farm through the probabilistic modelling of the business plan based on rating agencies methodologies (cash flow stochastic modelling and stress tests). This also provides sensitivity analysis on key risk factors on the business plan and a valuation of the project (cash flows NPV, IRR, minimum DSCR) at given confidence levels (VaR).

Securing the revenues of a wind farm project enhances the confidence and interest in the project for the financial community (better overview of the project profitability and validation of financial covenants for the debt).

The model includes in particular the following uncertain parameters:

- Delay on the construction start date

- Additional delay on the duration of the construction

- Availability of turbines

- Power outage (grid)

- Annual production of electricity (and wind speed)

- CER sale price/green certificate

- Operating cost annual increase

Based on stochastic and fixed assumptions, the model generates the full range of the potential scenario (see Figure 1).

The probability distribution of the project's cash flows allows one to assess the merits of various insurance options and in particular to test their benefits on the rating of the debt and the financial covenants.

Table 1 illustrates the results of various key financing indicators for various insurance options. It also provides an optimization of the debt/equity ratio.

Depending on the risk perception by the lenders, insurance terms may be amended (reduced retention or sub-limits) with a reasonable premium increase to ensure (at a certain confidence level) that the financial covenants will be met. This is a way of appraising the insurance cover in order to secure the project financing.

In addition, the sponsor of the project can use this technique to determine an optimum allocation of risks (and costs) between different parties involved in the project.

\footnotetext{
${ }^{1}$ UNEP (2007).
} 
ASSUMPTIONS

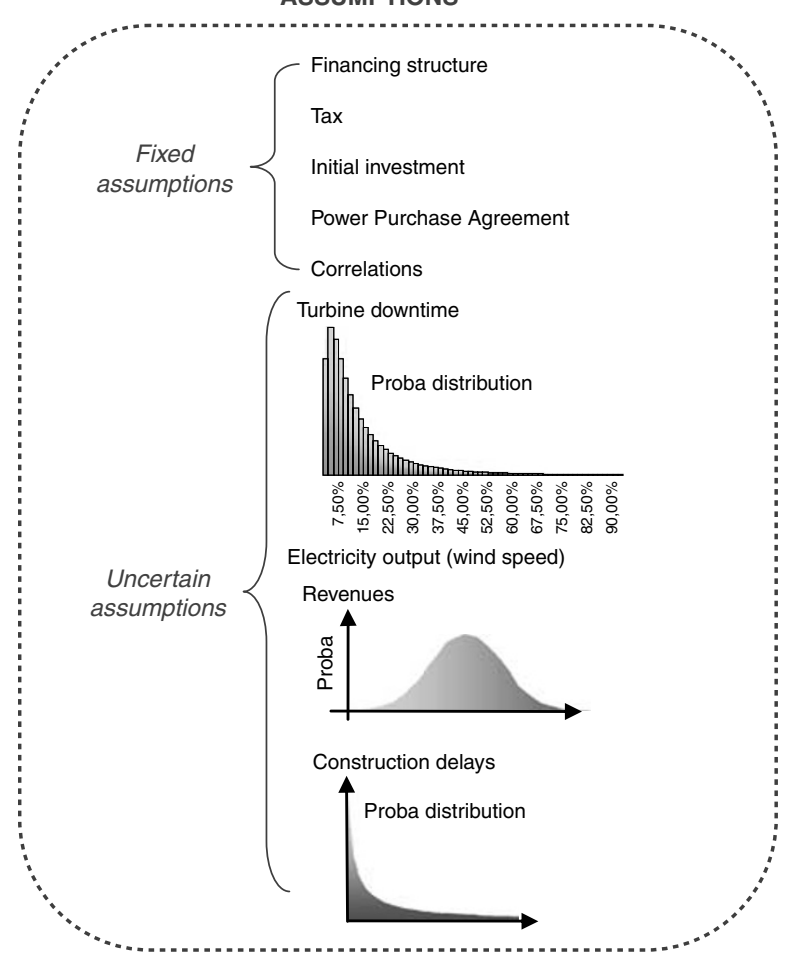

Figure 1. Risks analysis and financial impacts.
RESULTS

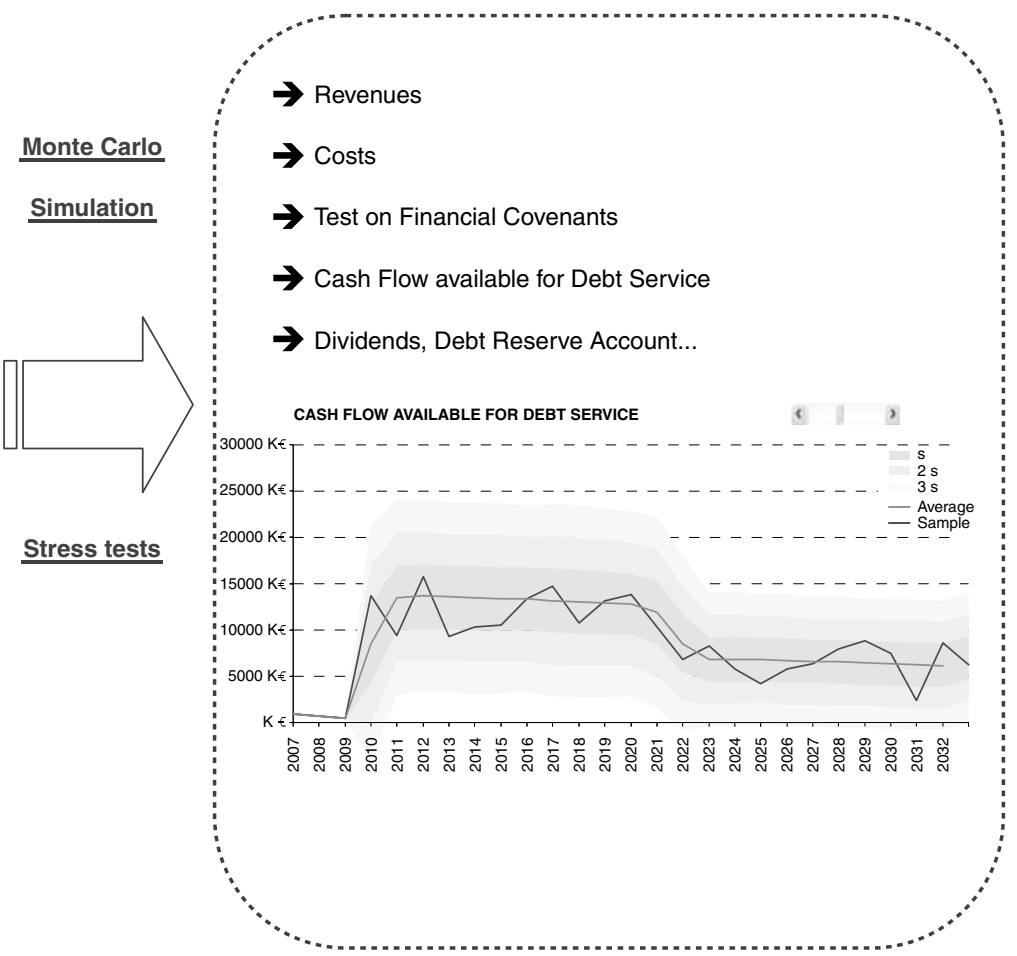


The Geneva Papers on Risk and Insurance - Issues and Practice

152

Table 1 Insurance benefits on key risk indicators

\begin{tabular}{|c|c|c|c|c|c|c|c|c|}
\hline $\begin{array}{l}\text { Optimized } \\
\text { debt/equity } \\
\text { ratio }\end{array}$ & $\begin{array}{c}\text { No } \\
\text { insurance } \\
60 / 40\end{array}$ & $\begin{array}{c}\text { Standard- } \\
\text { BI 66/34 }\end{array}$ & $\begin{array}{c}\text { Standard } \\
66 / 34\end{array}$ & $\begin{array}{c}\text { Political } \\
\text { risk } \\
70 / 30\end{array}$ & $\begin{array}{c}\text { CER } \\
\text { option } \\
66 / 34\end{array}$ & $\begin{array}{c}\text { Wind } \\
\text { derivative } \\
66 / 34\end{array}$ & $\begin{array}{c}\text { PolR }+C E R \\
\text { option } \\
70 / 30\end{array}$ & $\begin{array}{c}\text { PolR }+ \text { Wind } \\
D+C E R \\
\text { option } \\
66 / 34\end{array}$ \\
\hline Default rate $(\%)$ & 3.380 & 1.72 & 1.16 & 2.20 & 1.06 & 3.04 & 1.98 & 2.04 \\
\hline Indicative rating & Baa2 & A3 & A2 & A3 & A2 & Baal & A3 & A3 \\
\hline Average DSCR & 2.00 & 1.87 & 1.91 & 1.78 & 1.87 & 1.82 & 1.73 & 1.78 \\
\hline Minimum DSCR & 1.50 & 1.37 & 1.37 & 1.29 & 1.37 & 1.29 & 1.27 & 1.29 \\
\hline
\end{tabular}

Finally, because of a better assessment of the project's risks, a dedicated reserve can be established to finance the risk, or a liquidity line may be included in the financing structure to cover for instance the potential delay between the business interruption (BI) period (lack of revenue) and the actual BI loss indemnification by the insurer.

\title{
Appropriate risk assessment is a valuable exercise for the RE industry
}

Insurance is often perceived as a mandatory and costly cover to secure project financings and is rarely considered as a way of improving the overall financing conditions and perspectives.

For certain RE projects, such as wind farm or biomass, the use of such probabilistic models integrating the risks in the financing context provides a better overview of the risk potential impacts and the insurance merits.

This approach is particularly helpful in the RE sector, where an accurate risks assessment is an essential condition to the ultimate profitability of projects and where the availability of suitable insurance products is sometimes an issue.

\section{Reference}

UNEP (2007) Assessment of financial risk management instruments for renewable energy projects, UNEP Working group 1 Study Report, Paris, http://www.unep.fr/energy/projects/frm/frmi_WG1.htm.

\begin{abstract}
About the Author
Emmanuel Leblanc joined Marsh France in 2003 and is Head of the Structured Products team in charge of originating and arranging alternative risk transfer solutions for corporate clients. His team was recently involved in risk transfer analysis for Cat Nat exposure and was also a member of the United Nations Environmental Program working group for renewable energy. Prior to joining Marsh in 2003, he was Project Manager for AXA and Winterthur SRS. He was in charge of structuring and executing new solutions integrating capital market and insurance products. He started his career with BNP Paribas, where he spent 7 years in the Aircraft Finance Department. Emmanuel holds a Master of Management from ESC Le Havre.
\end{abstract}

